\title{
Correlation of blood sugar and lipid parameters with carotid intima media thickness among patients with type II diabetes mellitus
}

\author{
Kanakaraju K. ${ }^{1 *}$, Seetharaman Ranganathan $\mathrm{R}^{2}{ }^{2}$, Shankar R. ${ }^{3}$ \\ DOI: https://doi.org/10.17511/ijmrr.2019.i02.01 \\ 1* Kirubhakaran Kanakaraju, Assistant Professor, Department of Preventive and Social Medicine, Vinayaka Missions Kirupananda Variyar \\ Medical College and Hospital, Salem, Tamil Nadu, India. \\ 2 Rangabashyam Seetharaman Ranganathan, Professor and Head, Department of Preventive and Social Medicine, Vinayaka Missions \\ Kirupananda Variyar Medical College and Hospital, Salem, Tamil Nadu, India. \\ ${ }^{3}$ R. Shankar, Associate Professor, Department of Preventive and Social Medicine, Vinayaka Missions Kirupananda Variyar Medical College \\ and Hospital, Salem, Tamil Nadu, India.
}

Background: Of the various non invasive imaging methods available, arterial intima media thickness measurement obtained by B mode ultrasound is currently recommended by the American Heart Association as being relatively safe, non invasive and inexpensive method of assessing sub clinical atherosclerosis, and being an independent predictor of atherosclerotic events. Aim: To study the correlation between glycemic and lipid levels with carotid intima media thickness among patients with type II diabetes mellitus. Methodology: A prospective longitudinal study was conducted for a period of one year. Patients in the age group of 30 to 70 years with type II diabetes for more than 2 years were included as our study subjects. A total of 100 patients were included as our study subjects. Anthropometric measurements, blood sugar parameters and lipid parameters were measured as per the guidelines. Carotid artery intima media thickness was measured by B mode ultrasound having an electric transducer with a mid frequency of $7.5 \mathrm{MHz}$. Results: A multivariate analysis was performed to assess the various factors influencing the increase in the thickness of CIMT and among that we found a significant correlation had occurred with the factors like BMI, waist hip ratio, fasting and post-prandial blood sugar, HbA1C and among the lipid parameters LDL, total cholesterol and triglycerides had shown a statistical significant correlation $(p<.05)$, whereas factors like age, gender, hypertension status, duration of diabetes and HDL cholesterol among the lipid parameter did not show a statistical significant correlation with CIMT $(p>.05)$. Conclusion: CIMT measurement can be used as a regular screening tool in diabetic patients for the early detection of atherosclerosis among them.

Keywords: Carotid intima media thickness, Lipid parameters, Blood glucose parameters, Correlation

\section{Corresponding Author}

Kirubhakaran Kanakaraju, Assistant Professor, Department of Preventive and Social Medicine, Vinayaka Missions Kirupananda Variyar Medical College and Hospital, Salem, Tamil Nadu, India. Email: drkirubakaran@yahoo.com
How to Cite this Article

Kanakaraju K, Ranganathan R S, Shankar R. Correlation of blood sugar and lipid parameters with carotid intima media thickness among patients with type II diabetes mellitus. Int J Med Res Rev. 2019;7(2):54-60. Available From https://ijmrr.medresearch.in/index.php/ijmrr/article/ view/1036
To Browse

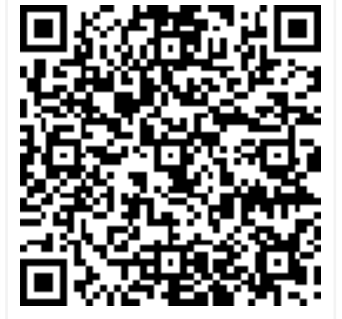

Manuscript Received 2019-03-10

Conflict of Interest No
Review Round 1 2019-03-20

Funding

Review Round 2
2019-03-25
Ethical Approval
Yes

Review Round 3

Plagiarism X-checker $6 \%$
Accepted 2019-03-29

Note

(c) 2019 by Kirubhakaran Kanakaraju, Rangabashyam Seetharaman Ranganathan, R. Shankar and Published by Siddharth Health Research and Social Welfare Society. This is an Open Access article licensed under a Creative Commons Attribution 4.0 International License https://creativecommons.org/licenses/by/4.0/ unported [CC BY 4.0]. 


\section{Introduction}

Globally, due to the demographic transition where the population of aged people was found to have a sharp increase over the past few decades, we also found a change in the epidemiology of diseases in which the prevalence of infectious diseases was found to come down and the prevalence of noncommunicable diseases had shown a steady increase. In India among the various noncommunicable diseases coronary artery disease is one of the most common ailments, as per the 2013 data deaths due to cardiovascular diseases accounts to one third of all deaths occurring globally $[1,2]$.

Diabetes considered being a major risk factor for CVD due to its oxidative stress on the endothelial walls and thereby causing endothelial dysfunction and consequently leading onto thickening of intima media [3]. Dyslipidemia with high triglycerides and LDL cholesterol and low HDL cholesterol, in type II diabetes patients would be a triggering factor in the development of atherosclerosis [4]. Carotid Intimal Medial Thickness (CIMT) is the area of tissue starting at the luminal edge of the artery and ending at the boundary between the media and the adventitia and it is a measure of subclinical atherosclerosis associated with cardio-vascular risk factors (CVRFs) and is predictive of stroke incident [5-8].

In healthy middle-aged adults it measures 0.6 to $0.7 \mathrm{~mm}$ and greater than $1.20 \mathrm{~mm}$ is considered abnormal. CIMT is age-dependent and increases at a rate of 0.005 to $0.010 \mathrm{~mm} /$ year [9]. Increase in CIMT can predict future events of silent brain infarction and coronary heart disease [10]. Of the various non invasive imaging methods available, arterial intima media thickness measurement obtained by B mode ultrasound is currently recommended by the American Heart Association as being relatively safe, non invasive and inexpensive method of assessing sub clinical atherosclerosis, and being an independent predictor of atherosclerotic events [11].

So, detection of atherosclerosis in the early phase by using CIMT is effective in arresting the progression of the disease by doing an early intervention and very few Indian studies had seen the association between CIMT and dyslipidemia and as well with diabetes and so the present study was conducted to assess and correlate the CIMT values with the glycemic levels and the lipid levels.

\section{Aim}

To study the association between glycemic and lipid levels with carotid intima media thickness among patients with type II diabetes mellitus.

\section{Methodology}

Study setting and study type: A prospective longitudinal study was conducted for a period of one year between April 2017 and March 2018 in our medical college hospital.

Ethical consideration: The study was started after getting the approval from the institutional ethical committee.

Inclusion criteria: Patients in the age group of 30 to 70 years with type II diabetes for more than 2 years were included as our study subjects.

Exclusion criteria: Type I diabetes patients and patients with history of coronary artery disease $(C A D)$, cerebrovascular disease (CVD), chronic kidney disease (CKD) and primary dyslipidemia were excluded from the study. Patients with history of alcohol and smoking were also excluded from the study.

Sampling method and sample collection: A total of 100 patients were included as our study subjects based on non-random quota sampling. Informed consent was obtained from all the patients involved in our study. A detailed history related to their diabetes status and risk factors was obtained from all patients and a complete general physical examination was conducted on all study subjects. Anthropometric measurements like BMI, waist hip ratio and blood pressure were measured on all patients based on routine guidelines. The fasting venous plasma glucose (FBS) and fasting lipid profile (FLP) were obtained after 12 hours of overnight fasting using the Olympus AU-400 Auto Analyzer and the 2 hour post prandial venous plasma glucose (PPBS) estimation was also done. The value of LDL was calculated using Freidewald's formula when the triglyceride was less than $400 \mathrm{mg} / \mathrm{dl}$ and direct estimation was done when the triglyceride was more than $400 \mathrm{mg} / \mathrm{dl}$. Dyslipidemia was defined based on National cholesterol education programme ATP 111 guidelines and the normal cut off values were taken as total cholesterol less than $200 \mathrm{mg} / \mathrm{dl}$; LDL less than $100 \mathrm{mg} / \mathrm{dl}$; triglyceride less than $150 \mathrm{mg} / \mathrm{dl}$ and values outside these limits were considered as abnormal. 
For HDL cholesterol a value less than $40 \mathrm{mg} / \mathrm{dl}$ was considered low and more than or equal to $60 \mathrm{mg} / \mathrm{dl}$ was considered high as per the ATP111 guidelines. HbA1c was estimated by column chromato-graphy method.

The patients were categorized as those having a $\mathrm{HbA} 1 \mathrm{c}$ of less than $8 \%$ which indicates good control of diabetes and those having more than $8 \%$ which indicates poor control of diabetes. Carotid artery intima media thickness was measured by $B$ mode ultrasound having an electric transducer with a mid frequency of 7.5 MHz. Scans were performed on both the right and left extracranial carotid arteries by trained personnel.

The IMT values were measured in six well defined arterial segments- near wall and far wall of distal $6 \mathrm{~mm}$ of common carotid, the carotid bulb and proximal $6 \mathrm{~mm}$ of internal carotid artery of both sides. The final IMT considered was the average of the IMT values at the 12 sites examined. Since IMT is considered as a candidate marker of cardiovascular risk, its normal value is interpreted in terms of increased risk rather than in terms of statistic distribution within a population. An upper limit of $0.9 \mathrm{~mm}$ was chosen for the present study based on epidemiological data currently available.

Statistical analysis: All data were entered and analysed using SPSS version 22. Mean and standard deviation was derived for all parametric variables and percentage was calculated for all parametric variables. Chi-square test was used to study the association between the two variables and pearson's correlation was used to assess the correlation between CIMT and lipid parameters and similarly CIMT and blood sugar parameters.

\section{Results}

The age wise distribution of the study subjects shoed that majority of the type II diabetes patients were in the age group between 40 and 60 years and the mean age was 55 years among males and 54 among females and there was almost near equal distribution of male and female patients (table 1 ).

Table-1: Age and gender wise distribution of the study subjects.

\begin{tabular}{|r|l|l|l|l|}
\hline Age & \multicolumn{1}{|c|}{ Male } & \multicolumn{1}{|c|}{ Female } & \multicolumn{1}{|c|}{ Total } & \multirow{2}{*}{ p value } \\
\hline $30-40$ & $2(4 \%)$ & $4(8 \%)$ & $6(6 \%)$ & \multirow{2}{*}{0.726} \\
\cline { 1 - 4 }$-51-50$ & $17(34.6 \%)$ & $12(23.5 \%)$ & $29(29 \%)$ & \\
\cline { 1 - 4 } $51-60$ & $14(28.5 \%)$ & $25(49 \%)$ & $39(39 \%)$ & \\
\cline { 1 - 4 } $61-70$ & $16(32.6 \%)$ & $10(19.6 \%)$ & $26(26 \%)$ & \\
\hline
\end{tabular}

\begin{tabular}{|l|l|l|l|l|}
\hline Total & $49(100 \%)$ & $51(100 \%)$ & $100(100 \%)$ & \multirow{2}{*}{} \\
\cline { 1 - 4 } Mean \pm SD & $55.5 \pm 9.3$ & $54.8 \pm 8.4$ & & \\
\hline
\end{tabular}

Table-2: Distribution of the study subjects based on the duration of diabetes.

\begin{tabular}{|c|c|c|c|c|}
\hline Duration of diabetes in years & Frequency & Percentage & Mean & SD \\
\hline $3-5$ & 60 & $60 \%$ & \multirow{7}{*}{4.65} & \\
\hline $5-7$ & 16 & $16 \%$ & & \\
\hline $7-9$ & 10 & $10 \%$ & & \\
\hline $9-11$ & 7 & $7 \%$ & & 3.9 \\
\hline $11-13$ & 3 & $3 \%$ & & \\
\hline$>13$ & 4 & $4 \%$ & & \\
\hline Total & 100 & $100 \%$ & & \\
\hline
\end{tabular}

In our study we included the patients with the history of diabetes for more than two years and more than $50 \%$ of them had the diabetes history between 3 and 5 years and the maximum duration was up to 15 years and the mean duration was 4.5 years (table 2 ).

Table-3: Mean and SD of the various blood parameters measured among the study subjects.

\begin{tabular}{|l|l|l|}
\hline \multicolumn{1}{|c|}{ Blood parameter } & \multicolumn{1}{|c|}{ Mean $(\mathrm{mg} / \mathrm{dl})$} & \multicolumn{1}{c|}{ SD } \\
\hline Fasting blood sugar & 162.2 & 69.6 \\
\hline Post-prandial blood sugar & 254.7 & 91.4 \\
\hline HbA1c & $7.35 \mathrm{gms} \%$ & 0.86 \\
\hline Total cholesterol & 243.9 & 72.4 \\
\hline Triglycerides & 184.5 & 67.4 \\
\hline LDL & 150.4 & 62 \\
\hline HDL & 47.5 & 4.3 \\
\hline
\end{tabular}

The mean of the various blood sugar and lipid parameters measured among the diabetes patients was shown in table 3 with a mean fasting, postprandial and HbA1C values of $162 \mathrm{mgs} / \mathrm{dl}, 254$ $\mathrm{mgs} / \mathrm{dl}$ and $7.3 \mathrm{gms} \%$ respectively and similarly all the lipid parameters like total cholesterol, triglycerides and LDL cholesterol was found to be above normal except for HDL which was found to be in normal limits.

Table-4: Mean and SD of CIMT of both sides.

\begin{tabular}{|l|l|l|}
\hline \multicolumn{1}{|c|}{ CIMT } & \multicolumn{1}{|c|}{ Mean $(\mathrm{mm})$} & \multicolumn{1}{c|}{ SD } \\
\hline CIMT right side & 0.80 & 0.52 \\
\hline CIMT left side & 0.84 & 0.55 \\
\hline
\end{tabular}

The carotid intima media thickness was measured among both sides and the mean CIMT of right side was $0.80 \mathrm{~mm}$ and in left side it was $0.84 \mathrm{~mm}$ and the thickness was almost similar among both sides (table 4). 
Table-5: Association and correlation between CIMT and blood sugar parameters.

\begin{tabular}{|c|c|c|c|c|}
\hline \multirow{2}{*}{$\begin{array}{l}\text { Blood sugar } \\
\text { parameter }\end{array}$} & \multicolumn{2}{|c|}{ CIMT (right side) } & \multicolumn{2}{|c|}{ CIMT (left side) } \\
\hline & $\begin{array}{l}\text { Correlation } \\
*\end{array}$ & $\begin{array}{l}\text { Association* } \\
*\end{array}$ & Correlation & $\begin{array}{l}\text { Association* } \\
*\end{array}$ \\
\hline FBS & 0.237 & $<.0001$ & 0.224 & $<.0001$ \\
\hline PPBS & 0.314 & $\mid<.0001$ & 0.323 & $<.0001$ \\
\hline $\mathrm{HbA} 1 \mathrm{C}$ & 0.370 & $<.0001$ & 0.368 & $<.0001$ \\
\hline
\end{tabular}

**- association was assessed using unpaired $\mathrm{T}$ test

Carotid intima media thickness was found to have a strong significant statistical association with the blood sugar parameters whereas correlation shows only a weak positive correlation between these two parameters and similarly association between CIMT and lipid parameters had shown a significant association and the correlation was almost similar to the blood sugar parameters (table 5 and 6 )

Table-6: Association and correlation between CIMT and lipid parameters.

\begin{tabular}{|l|l|l|l|l|}
\hline \multirow{2}{*}{ Lipid parameter } & \multicolumn{2}{|c|}{ CIMT (right side) } & \multicolumn{2}{c|}{ CIMT (left side) } \\
\cline { 2 - 5 } & Correlation * & Association** & Correlation * & Association** \\
\hline TC & 0.284 & $<.0001$ & 0.281 & $<.0001$ \\
\hline Triglycerides & 0.220 & $<.0001$ & 0.219 & $<.0001$ \\
\hline LDL & 0.279 & $<.0001$ & 0.282 & $<.0001$ \\
\hline HDL & -0.103 & $<.0001$ & 0.110 & $<.0001$ \\
\hline
\end{tabular}

*-correlation was assessed using pearson's correlation

**- association was assessed using unpaired $\mathrm{T}$ test

Table-7: Multivariate analysis of factors influencing the carotid intima media thickness.

\begin{tabular}{|l|l|l|l|l|}
\hline \multicolumn{1}{|c|}{ Factor } & Co-efficient & Std. error & F test & P value \\
\hline Age & 0.205 & 0.144 & 0.781 & 0.349 \\
\hline Gender & 0.139 & 0.098 & 0.709 & 0.298 \\
\hline Duration of diabetes & 0.219 & 0.129 & 0.665 & 0.0721 \\
\hline BMI & 0.321 & 0.133 & 3.865 & 0.017 \\
\hline W/H ratio & 0.336 & 0.165 & 3.590 & 0.005 \\
\hline Hypertension & 0.199 & 0.082 & 0.928 & 0.199 \\
\hline FBS & 0.237 & 0.142 & 2.995 & 0.0431 \\
\hline PPBS & 0.314 & 0.168 & 3.517 & 0.0217 \\
\hline HbA1C & 0.370 & 0.121 & 3.918 & 0.0210 \\
\hline LDL & 0.279 & 0.151 & 2.981 & 0.0287 \\
\hline TC & 0.284 & 0.067 & 3.126 & 0.0265 \\
\hline Triglycerides & 0.220 & 0.187 & 2.109 & 0.0487 \\
\hline HDL & -0.103 & 0.132 & 1.092 & 0.0921 \\
\hline
\end{tabular}

A multivariate analysis was performed to assess the various factors influencing the increase in the thickness of CIMT and among that we found a significant correlation had occurred with the factors like BMI, waist hip ratio, fasting and post-prandial blood sugar, $\mathrm{HbA} 1 \mathrm{C}$ and among the lipid parameters $\mathrm{LDL}$, total cholesterol and triglycerides had shown a statistical significant correlation $(p<.05)$, whereas factors like age, gender, hypertension status, duration of diabetes and HDL cholesterol among the lipid parameter did not show a statistical significant correlation with CIMT ( $p>.05)$ (table 7).

\section{Discussions}

The detection of atherosclerosis in an early stage can be done by suing ultrasound $B$ mode by measuring the carotid intima media thickness in asymptomatic patients with cardiovascular diseases. Previous studies had proven that the thickness of CIMT as an individual predictor for atherosclerosis and had also identified certain factors responsible for the increase in thickness and in the present study we tried to associate and correlate the values of blood sugar and lipid parameters with that of the CIMT $[12,13]$. The mean CIMT in the present study was found to be $0.83 \mathrm{~mm}$ and it was found to be slightly higher among males than the females. Similar type of study done in Chennai had shown the mean value of CIMT as $0.95 \mathrm{~mm}$ and a study done by Gayathri et al had shown the mean CIMT value as 0.935 [14]. Females had a relatively lower value of CIMT as compared to males possibly due to the protective effect of female hormones and/or male gender being at a higher risk of atherosclerosis. Similar results have been reported by Kraml et al who also observed significant higher IMT in men than women [15]. The present study showed that the anthropometric measurements mainly the BMI and waist hip ratio had shown a statistical significant correlation with CIMT values and a similar type of results was also shown by Masoud Manaviat et al [16]. A study by Frouse et al on association of obesity and central fat distribution with carotid artery wall thickening had shown an independent association between general and abdominal obesity reflected by high BMI and WHR respectively and carotid wall thickening [17]. Waist hip ratio was found to be an independent determinant of intima media thickness even after multivariate analysis. Our study had shown a significant association and correlation between various blood sugar parameters like FBG, PPBG and $\mathrm{HbA} 1 \mathrm{c}$ with the CIMT values. 
The relationship between the level of FBG and CIMT has been controversial. Previous studies have shown that there was no significant association between IFG and CIMT after adjustment by covariates $[18,19]$.

The associations between hyperglycemia and CIMT were significant in univariate analyses, but disappeared after adjustment for age, sex and anthropometric variables [20,21]. Furthermore, other studies have shown that higher HbA1c levels were significantly and independently related to increased CIMT, but IFG was not $[22,23]$.

The most recent study in community dwelling Japanese older adults showed that elevated IFG was significantly associated with increased CIMT [24]. Consistent with that study, in the present study, we found a significant relationship between FBG and mean CIMT. The current study had proven that after multivariate analysis the correlation between the various lipid parameters like LDL, total cholesterol and triglyceride levels had shown a statistical significant correlation with CIMT.

Previous studies have also shown that low apolipoprotein A1 levels, and elevated LDL-C and apolipoprotein $B$ levels in childhood predict increased CIMT in adulthood, and that a high LDL-C concentration predisposes to the progression of subclinical atherosclerosis $[25,26]$.

LDL particles have been suggested to predict an increased risk of atherosclerotic diseases because of their toxicity to the endothelium and underlying smooth muscle, adhesion to glycosaminoglycans in the endothelial basement membrane, and high susceptibility to scavenger receptors on macrophages [27].

However, the association between TG and CIMT has been unclear, especially in low-income populations. Numerous studies have shown that there was a positive association between TG and CIMT; two longitudinal studies reported a positive association between baseline TG levels and progression of CIMT $[27,28]$.

Among the various lipid parameters in our study we didn't find a strong negative correlation between HDL cholesterol and the CIMT values and a similar type of results was also established in a Chinese study done by Liu Gao etal and most of the other studies had also proven that no significant correlation had existed between the HDL levels and the CIMT values.

\section{Conclusion}

As of today the prevalence of atherosclerosis among diabetes patients are in an increasing trend. Assessment of carotid artery intima media thickness by $B$ mode ultrasound is a proxy measure for early detection of atherosclerosis and also a more costeffective tool and so early interventions can be taken in preventing major complications like stroke or cardiovascular diseases. Both the blood sugar and the lipid parameters had a statistical significant correlation with carotid intima media thickness along with BMI and waist hip ratio, whereas age, gender, hypertension status and duration of diabetes did not show any association with CIMT. So CIMT measurement can be used as a regular screening tool in diabetic patients for the early detection $\mathrm{f}$ atherosclerosis among them.

\section{Contribution by authors}

01. Kirubhakaran Kanakaraju: data collection and preparing the manuscript

02. Rangabashyam

Seetharaman

Ranganathan: methodology preparation and helping in manuscript writing

03. Dr R Shankar: statistical analysis and deriving statistical inference.

\section{What this study adds to the existing knowledge}

Measuring the carotid intima media thickness and correlating it with blood sugar levels and lipid parameters would help in detecting the atherosclerosis in the early phase among type II diabetes patients.

\section{Reference}

01. Mohan V, Deepa R, Rani SS, et al. Prevalence of coronary artery disease and its relationship to lipids in a selected population in South IndiaThe Chennai Urban Population Study (CUPS No 5). J Am Coll Cardiol. 2001 Sep;38(3)682-7. [Crossref]

02. Gupta R, Gupta VP, Sarna M. Prevalence of coronary heart disease and risk factors in an urban Indian population- Jaipur Heart Watch-2. Indian Heart J. $2002 ; 54 ; 59-66$.

[Crossref] 
03. Mohan V, Sandeep S, Deepa $R$, et al. Epidemiology of type 2 diabetes- Indian scenario. Indian J Med Res. 2007 Mar;125(3)217-30.

[Crossref]

04. Farmer JA. Diabetic dyslipidemia and atherosclerosis- evidence from clinical trials. Curr Diab Rep. 2008 Feb;8(1)71-7.

[Crossref]

05. Matsumoto K, Sera $Y$, Nakamura $H$, et al. Correlation between common carotid arterial wall thickness and ischemic stroke in patients with type 2 diabetes mellitus. Metabolism. 2002 Feb;51(2)244-7.

[Crossref]

06. Touboul PJ, Elbaz A, Koller C, et al. Common carotid artery intima-media thickness and brain infarction the Etude du Profil Génétique de I'Infarctus Cérébral (GENIC) case-control studyThe GENIC Investigators. Circulation. $2000 \mathrm{Jul}$ $18 ; 102(3) 313-8$.

[Crossref]

07. Kitamura A, Iso $H$, Imano $H$, et al. Carotid intima-media thickness and plaque characteristics as a risk factor for stroke in Japanese elderly men. Stroke. 2004 Dec;35(12)2788-94. Epub 2004 Nov 4. DOI: 10.1161/01.STR.0000147723.52033.9e [Crossref]

08. Hollander $M$, Hak AE, Koudstaal PJ, et al. Comparison between measures of atherosclerosis and risk of stroke- the Rotterdam Study. Stroke. 2003 Oct;34(10)2367-72.

DOI: $\quad 10.1161 / 01 . S T R .0000091393 .32060 .0 \mathrm{E}$ [Crossref]

09. Jacoby DS, Mohler III ER, Rader DJ. Noninvasive atherosclerosis imaging for predicting cardiovascular events and assessing therapeutic interventions. Curr Atheroscler Rep. 2004 Jan;6(1)20-6.

[Crossref]

10. Bernard S, Sérusclat A, Targe $F$, et al. Incremental predictive value of carotid ultrasonography in the assessment of coronary risk in a cohort of asymptomatic type 2 diabetic subjects. Diabetes Care. 2005 May;28(5)115862.

[Crossref]
11. Mukherjee D, Yadav JS. Carotid artery intimalmedial thickness- indicator of atherosclerotic burden and response to risk factor modification. Am Heart J. 2002 Nov;144(5)753-9. [Crossref]

12. Bots ML, Dijk JM, Oren A, et al. Carotid intimamedia thickness, arterial stiffness and risk of cardiovascular disease- current evidence. J Hypertens. 2002 Dec;20(12)2317-25. [Crossref]

13. Teno $S$, Uto $Y$, Nagashima $H$, et al. Association of postprandial hypertriglyceridemia and carotid intima-media thickness in patients with type 2 diabetes. Diabetes Care. 2000 Sep;23(9)14016.

[Crossref]

14. Gayathri R, Chandni R, Udayabhaskaran V, et al. Carotid artery intima media thickness in relation with atherosclerotic risk factors in patients with type2 diabetes mellitus. J Assoc Physicians India. 2012 Sep;60;20-4.

[Crossref]

15. Kraml, Potockova J, Andel M, Zvarova J, Stefek M. Sonographic measurement of intimal thickness of the common carotid artery in diabetics. Vnitr Lek. 1999;45;457-62.

[Crossref]

16. Masoud R Manaviat, Mohammad Afkhami, Mohammad R Shoja. Retinopathy and microalbuminuria in type II diabetic patients. BMC Ophthalmology. 2004;4;9.

doi: $10.1186 / 1471-2415-4-9$ [Crossref]

17. rouse JR 3rd, Thompson CJ. An evaluation of methods for imaging and quantifying coronary and carotid lumen stenosis and atherosclerosis. Circulation. 1993 Mar;87(3 Suppl)II17-33. [Crossref]

18. Goya K, Kitamura T, Inaba M, et al. Risk factors for asymptomatic atherosclerosis in Japanese type 2 diabetic patients without diabetic microvascular complications. Metabolism. 2003; 52;1302-1306.

[Crossref]

19. Temelkova-Kurktschiev TS, Koehler C, Henkel E, et al. Post challenge plasma glucose and glycemic spikes are more strongly associated with atherosclerosis than fasting glucose or HbA1c level. Diabetes Care. 2000 Dec;23(12)1830-4.

¡Crossref] 
20. Temelkova- Kurktschiev T, Koehler C, Schaper F, et al. Relationship between fasting plasma glucose, atherosclerosis risk factors and carotid intima media thickness in non-diabetic individuals. Diabetologia. 1998;41;706-712.

[Crossref]

21. Kowall B, Ebert N, Then C, et al. Associations between blood glucose and carotid intima-media thickness disappear after adjustment for shared risk factors- the KORA F4 study. PLoS One. 2012;7;e52590.

[Crossref]

22. Huang Y, Bi Y, Wang W, et al. Glycated hemoglobin A1C, fasting plasma glucose, and two-hour post challenge plasma glucose levels in relation to carotid intima-media thickness in Chinese with normal glucose tolerance. J Clin Endocrinol Metab. 2011;96;E1461-E1465.

[Crossref]

23. Hung CS, Lee PC, Li HY, et al. Haemoglobin A1C is associated with carotid intima-media thickness in a Chinese population. Clin Endocrinol (Oxf). 2011 Dec;75(6)780-5.

doi: 10.1111/j.1365-2265.2011.04129.x [Crossref]

24. Mukai N, Ninomiya T, Hata J, et al. Association of hemoglobin A1C and glycated albumin with carotid atherosclerosis in community-dwelling Japanese subjects- the Hisayama Study. Cardiovasc Diabetol. 2015;14;84.

[Crossref]
25. Koskinen J, Kähönen M, Viikari JS, et al. Conventional cardiovascular risk factors and metabolic syndrome in predicting carotid intimamedia thickness progression in young adultsthe cardiovascular risk in young Finns study. Circulation. 2009 Jul 21;120(3)229-36. doi: 10.1161/CIRCULATIONAHA.108.845065 [Crossref]

26. Carmena R, Duriez $P$, Fruchart JC. Atherogenic lipoprotein particles in atherosclerosis. Circulation. 2004 Jun 15;109(23 Suppl 1)III2-7. DOI: 10.1161/01.CIR.0000131511.50734.44 [Crossref]

27. Bokemark L, Wikstrand J, Attvall S, et al. Insulin resistance and intima-media thickness in the carotid and femoral arteries of clinically healthy 58-yearold men- The Atherosclerosis and Insulin Resistance Study (AIR). J Intern Med. 2001;249;59-67.

[Crossref]

28. Fan AZ. Metabolic syndrome and progression of atherosclerosis among middle-aged US adults. J Atheroscler Thromb. 2006 Feb;13(1)46-54. [Crossref]

29. Liu Gao, Lingling Bai, Min Shi, Jingxian Ni, Hongyan Lu. Association between carotid intima-media thickness and fasting blood glucose level- A population-based crosssectional study among low-income adults in rural China. J Diabetes Investig. 2017 Nov;8(6)88-98.

[Crossref] 